\title{
Utilização de modelos membranares na avaliação da actividade de fármacos
}

\author{
HELENA FERREIRA, MARLENE LÚCIO, CHRISTOPHE SIQUET, SALETTE REIS*
}

A importância do conhecimento das interacções de uma substância farmacologicamente activa com as membranas biológicas deve-se, principalmente, aos efeitos que estas podem exercer na sua eficácia terapêutica por condicionarem a sua biodisponibilidade ou por terem um papel primordial no seu mecanismo de acção.

Estas interacções dependem simultaneamente das propriedades das próprias membranas, determinadas pela respectiva composição, mas também das propriedades físico-químicas dos próprios fármacos. O conhecimento integral das interacções dos fármacos com as membranas lipídicas é assim de extrema relevância na elucidação do seu modo de acção, não só quando este está dependente da ligação a receptores membranares, mas também no caso da actividade dos fármacos ser inerente à sua entrada na célula. As relações que se possam estabelecer entre o mecanismo de acção de um fármaco e o seu comportamento face às membranas biológicas permitirá ainda estabelecer uma relação causa-efeito entre as características físico-químicas dos compostos e os respecti- vos perfis farmacológicos, de tal modo que será possível desenvolver o conceito de relação estrutura-actividade de forma a criar novos compostos com maior eficácia terapêutica e com menores efeitos secundários indesejáveis. Com base no exposto, pretende-se no presente trabaIho apresentar, de uma forma geral, os efeitos que os fármacos podem exercer, directa ou indirectamente, ao nível das propriedades físico-químicas das membranas biológicas e a importância da avaliação desses efeitos no conhecimento dos respectivos mecanismos de acção. São descritas e discutidas as metodologias usualmente utilizadas na avaliação das interacções fármaco - matriz lipídica, baseadas na avaliação da alteração das propriedades físico-químicas do fármaco, da própria membrana ou de uma sonda exógena e que permitem a avaliação do coeficiente de partição do fármaco, a localização do fármaco na matriz lipídica, a avaliação do efeito da presença do fármaco na fluidez da membrana e na carga superficial da membrana e ainda na estabilidade dos fosfolípidos membranares.

\section{Introdução}

Um dos mais importantes aspectos estruturais da organização biológica é a presença de uma membrana delimitadora de tal modo que a própria unidade básica da vida - a célula - é definida física e funcionalmente por uma membrana celular. Compreender os sistemas biológicos, requer portanto uma familiaridade com a química e a física das membranas biológicas.

As membranas celulares constituem a primeira estrutura biológica encontrada pelos fármacos. De facto, durante o trajecto de uma substância activa desde

*REQUIMTE/Departamento de Química-Física, Faculdade de Farmácia, Universidade do Porto, Rua Aníbal Cunha, 164, 4099-030 Porto, Portugal o seu local de absorção até aos locais onde a sua acção será exercida, é inevitável a passagem de variadas barreiras lipídicas formadas pelas membranas celulares, estruturalmente constituídas por uma bicamada de fosfolípidos onde se encontram incluídas proteínas, glicoproteínas e outros constituintes. As ligações ou interacções dos fármacos com os componentes lipídicos da membrana podem ser responsáveis pela sua acção tóxica ou podem igualmente explicar o seu modo de acção uma vez que estes fármacos podem actuar a um nível membranar ou podem ter que passar através de membranas antes de atingirem um alvo intracelular. Da interacção fármaco-membranas pode ainda resultar uma alteração das propriedades físico-químicas da própria membrana que, por si só, pode contribuir de uma forma directa para o seu mecanismo de acção ou, consequentemente, originar uma alteração da actividade das enzimas membranares. O conhecimento exaustivo da interacção dos fármacos com as membranas lipídicas é crucial para a compreensão dos parâmetros de distribuição dessas moléculas no organismo, bem como para o estabelecimento das relações entre as suas propriedades físico-químicas e os parâmetros farmacológicos apresentados, relações importantes no estudo e desenho de novos compostos com maior eficácia terapêutica e com menores efeitos secundários, a maior parte das vezes indesejáveis.

A complexidade, o número e diversidade de factores envolvidos e operantes no mesmo fenómeno que ocorre na mem- 
brana celular, faz com que os estudos físico-químicos nem sempre possam ser realizados in vivo usando sistemas celulares. Assim, e numa primeira fase, podem utilizar-se sistemas in vitro, muito simples, que simulem pequenas partes desses sistemas complexos. A partir da informação retirada com estes sistemas podem usar-se sistemas de maior complexidade, numa contínua aproximação dos sistemas biológicos reais, de forma a obter dados que possam ser extrapolados para situações in vivo.

O conhecimento químico das estruturas membranares tem permitido, então, de uma forma progressiva, desenvolver e aperfeiçoar modelos cada vez mais harmonizados com as funções de mimetização dos processos mediados pelas membranas. Dos diversos modelos de biomembranas desenvolvidos os lipossomas e as micelas são as estruturas que mostram ser mais adequadas e que melhor ilustram a interacção dos fármacos com as biomembranas, uma vez que, estes micro-agregados, e em especial os lipossomas, apresentam o ambiente químico e anisotrópico observado nas membranas biológicas. Para além disso, o seu manuseamento é mais fácil e mais reprodutível do que a utilização de células ou tecidos animais, já que as micelas e os lipossomas podem ser fácil e homogeneamente preparados, e as suas propriedades físicas bem caracterizadas.

\section{Utilização de modelos de biomembranas no estudo da interacção de fármacos}

\section{Tipos de modelos de biomembranas}

Os surfactantes, geralmente designados por detergentes, são moléculas anfifílicas que possuem uma "cabeça" hidrofílica (polar) e uma "cauda" hidrofóbica (apolar) (Figura 1).

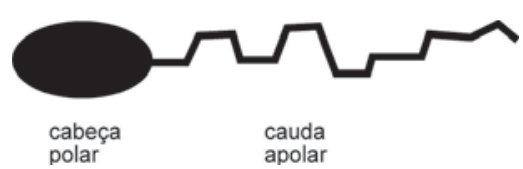

Os monómeros livres de agentes anfifílicos têm a capacidade de se dissolver em água numa determinada concentração formando-se monocamadas de surfactante na interface solvente/ar (Figura 2). Acima dessa gama estreita de concentração há uma transição súbita nas propriedades físicas dos surfactantes. Esta transição corresponde à concentração a partir da qual se torna termodinamicamente favorável a formação de agregados e é definida como concentração micelar crítica ou CMC. A auto-agregação dos agentes anfifílicos em água leva à formação de estruturas que dependem da contribuição relativa das regiões hidrofóbicas e hidrofílicas da molécula. Agentes anfifílicos com uma só cadeia hidrocarbonada, ou duas cadeias curtas formam micelas em solução aquosa, organizando-se de forma a maximizarem a superfície de exposição dos seus grupos polares ao meio aquoso e evitando a existência de interfaces entre as suas partes hidrófobicas e a água. De acordo com a ocupação espacial relativa dos grupos polares ou apolares das moléculas anfifílicas, assim os agregados resultantes apresentam formas diferentes (Figura 2). Quando as moléculas de surfactante exibem uma configuração cónica, possuindo uma área de "cabeça" elevada e uma "cauda" única, tendem a formar micelas esféricas. Se a área da "cabeça" diminuir em relação à "cauda", o agregado formado assumirá a forma de bastonete. Agentes anfifílicos com dupla cadeia apolar e valores baixos de área polar tendem a formar micelas inversas especialmente em solvente apolar [1].

Por outro lado, agentes anfifílicos contendo duas cadeias hidrocarbonadas longas possuem a capacidade de, espontaneamente, formar agregados em bicamada, que assumem a forma de uma estrutura esférica e fechada (vesícula) quando dispersos em solução aquosa. As vesículas compostas de fosfolípidos são usualmente denominadas lipossomas (Figura 3), enquanto que o termo genérico vesícula é atribuído às estruturas formadas por outros agentes anfifílicos [2]. Estas estruturas fechadas envolvem um determinado volume de solução aquosa, variando o seu tamanho desde alguns nanómetros a micrómetros de diâmetro [3, 4]. Sem qualquer processamento adicional, a dispersão de fosfolípidos em água origina uma população polidispersa denominada MLV ("multilamellar vesicles"- vesículas multilamelares), cujos tamanhos estão geralmente compreendidos entre 0,4 e 3,5 um de diâmetro (Figura 3B). Cada vesícula consiste em várias lamelas lipídicas (à volta de cinco ou mais) dispostas concentricamente, entre as quais se dispõe uma fracção do meio aquoso interno. Os lipossomas formados por uma única camada são denominados LUV ("large unilamellar vesicles"- vesículas
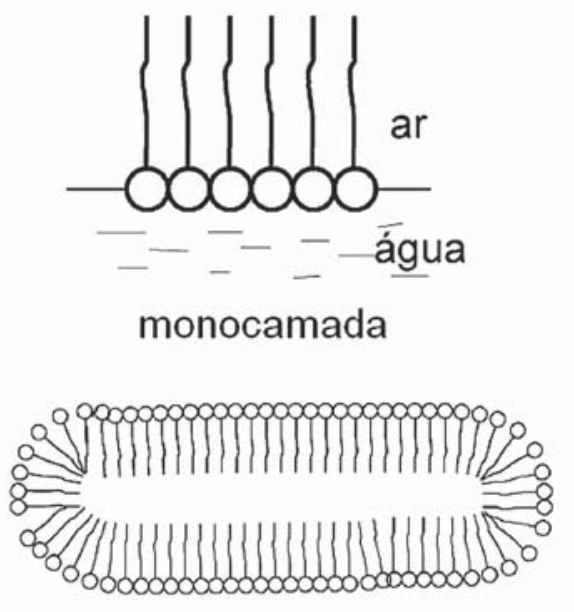

micela em forma de bastonete
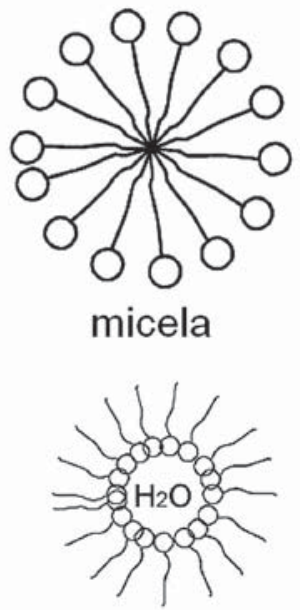

micela inversa

Figura 1 Composto anfifílico

Figura 2 Agentes miméticos das membranas. Micelas 


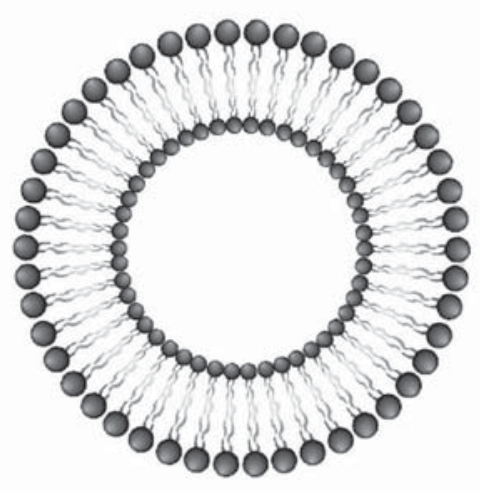

A

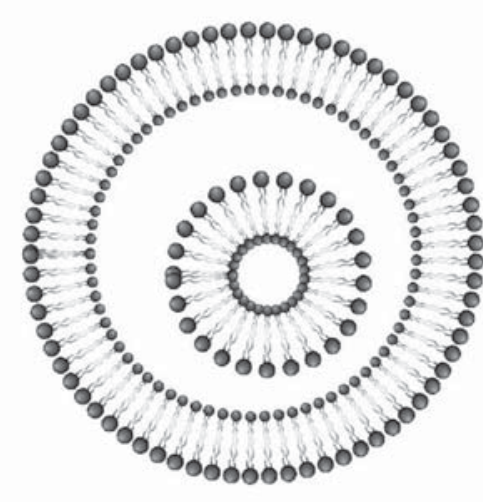

B

Figura 3 Agentes miméticos das membranas. Lipossomas. A: LUV, B: MLV

unilamelares) se o seu tamanho for superior a $50 \mathrm{~nm}$ segundo alguns autores [1, 3] (Figura 3A). Os SUV ("small unilamellar vesicles") são caracterizados por diâmetros aproximados de 25 a 50 nm e os IUV ("intermediate-sized unilamellar vesicles") por tamanhos intermédios $[1,3]$.

A carga da parte polar das moléculas anfifílicas determina grande parte das suas propriedades físico-químicas, pelo que é base da classificação mais usual dos agentes anfifílicos, que se dividem em aniónicos, catiónicos, zwitteriónicos e não iónicos. Os agregados são também caracterizados pela parte polar dos surfactantes que os constituem. As micelas são geralmente de origem sintética e a oferta extensa dos diferentes tipos de surfactantes permite usá-las para mimetizar as interacções físico-químicas como se fossem modelos de biomembranas extremamente simplificados, apresentando apenas dois compartimentos. Como exemplo de micelas iónicas apresenta-se as constituídas por brometo de cetiltrimetilamónio (CTAB), por dodecilsulfato de sódio (SDS) e por hexadecilfosfocolina (HDPC) (Figura 4) que formam, respectivamente, micelas aniónicas, catiónicas e zwiteriónicas [5]. Os surfactantes não-iónicos têm uma parte polar, sem carga associada, formada por grupos com uma grande afinidade para a água tais como álcool nos glicerideos ou açúcar nos glicolípidos.

As micelas de HDPC devido à presença do grupo fosfocolina zwitteriónico, exibem uma evidente similaridade estru- tural com os fosfolípidos presentes nas membranas biológicas. As micelas têm a vantagem de serem agregados estáveis, fáceis de preparar, muito homogéneos e apresentando menos interferências nas medidas, nomeadamente espectroscópicas, devido ao seu tamanho. Têm vindo, assim, a ser utilizados como modelos para estudos de interacções de moléculas e iões com membranas lipídicas, constituindo um modelo prático e facilmente manipulável.

A escolha dos surfactantes que formam os lipossomas é mais restrita, pois, embora se usem fosfolípidos sintéticos, a preferência vai para os compostos de origem natural. Os fosfolípidos contendo colina (fosfatidilcolina), geralmente denominados lecitinas (Figura 5), são os mais abundantes na natureza (encontram-se na gema dos ovos e na soja) e constituem o maior componente das membranas naturais, sendo portanto bastante utilizados na formação de lipossomas para as mais variadas aplicações. As lecitinas são moléculas zwitteriónicas a $\mathrm{pH}$ fisiológico e possuem a vantagem de se poder manusear à temperatura ambiente sendo relativamente inertes quimicamente e passíveis de serem obtidas a baixo custo. Exigem apenas alguns cuidados na preparação das vesículas como sejam a preparação na ausência de luz e de oxigénio, uma vez que os fosfolípidos são sensíveis à temperatura, ao oxigénio/luz e aos agentes oxidantes.

Mais ainda do que as micelas que, apesar de serem modelos simples, apresentam relativa falta de semelhança estrutural com os sistemas que pretendem mimetizar, os lipossomas constituem modelos valiosos das membranas biológicas pois, sendo compostos pelos mesmos constituintes das membranas naturais, formam uma estrutura idêntica a estas.

Tendo em conta que as interacções dos fármacos com as biomembranas dependem da composição química das próprias membranas, é frequente preparar lipossomas introduzindo na sua estrutura diferentes constituintes, para além dos fosfolípidos, nomeadamente colesterol ou mesmo enzimas membranares, mantendo a actividade destas 
em microambientes muito semelhantes aos reais. Estes lipossomas constituem sistemas de maior complexidade, numa contínua aproximação dos sistemas biológicos reais.

As interacções dos fármacos com as biomembranas dependem ainda das propriedades físico-químicas dos próprios fármacos. Assim sendo, a interacção de um fármaco com a membrana depende da sua lipofilia que condiciona igualmente a sua localização. Na Figura 6 apresenta-se de uma forma esquematizada estes dois aspectos que influenciam o tipo de interacções fármaco-membrana. Por um lado mostra-se como diferentes constituintes inseridos na estrutura lipídica (como os surfactantes aniónicos) vêem acrescentar a possibilidade de interacção com diferentes compostos (neste caso estende a possibilidade de interacção com compostos catiónicos). Por outro lado, ilustra-se a relevância das características físico-químicas dos fármacos na localização na matriz lipídica de lipossomas, apresentando os fármacos localizações diferentes conforme a sua carga e lipofilia.

\section{Preparação dos modelos de biomembranas}

Preparação de micelas - As soluções micelares são preparadas por pesagem do surfactante, seguida de diluição em água ou tampão apropriado.

Preparação de lipossomas - Os lipossomas podem ser preparados pelo método clássico de hidratação do filme lipídico [4]. Segundo este método, a quantidade necessária de lípido dissolvida num solvente orgânico, é evaporada à secura sob corrente de um gás inerte. O filme lipídico preparado é posteriormente hidratado com tampão apropriado. Após agitação da mistura em vórtice, forma-se uma população de vesículas lipossómicas heterogénea no que respeita ao tamanho e número de bicamadas lipídicas. Os lipossomas assim preparados são denominados por lipossomas multilamelares (MLVs) e são usados sem qualquer processamento adicional nos estudos com este tipo de estruturas. No entanto, a utilização de lipossomas como simuladores de sistemas naturais implica, muitas vezes, o uso de vesículas com propriedades bem definidas com vista à

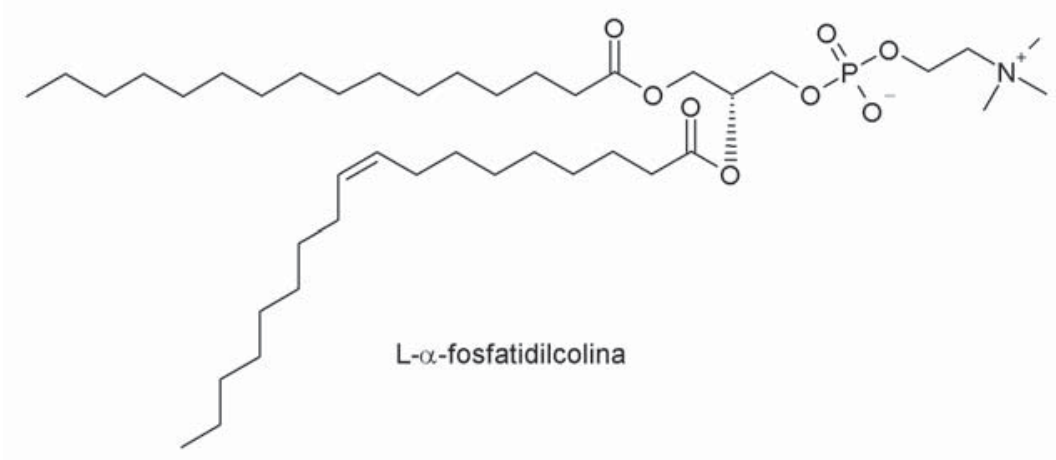

Figura 5 Lecitina compreensão do impacto de cada factor na membrana. Neste sentido, os LUVs, apresentando uma única membrana e um volume de solução aquosa razoavelmente grande no seu interior, têm maior interesse prático. Para a obtenção de LUVs a partir de MLVs é necessário recorrer a processos adequados como por exemplo a sonicação ou extrusão. De acordo com o método de extrusão (Figura 7), as dispersões de MLVs passam sob pressão através de filtros de policar- bonato, de diâmetro de poro bem definido. Após várias passagens consecutivas pelo filtro, em ambiente de gás inerte e a uma temperatura superior à transição de fase dos lípidos constituintes, obtêm-se os lipossomas unilamelares (LUVs) (Figura 3A).

A concentração final de fosfolípido pode ser determinada pelo método do fosfomolibdato modificado [6]. Este método baseia-se na mineralização do fósforo presente nos fosfolípidos a fosfato inor-

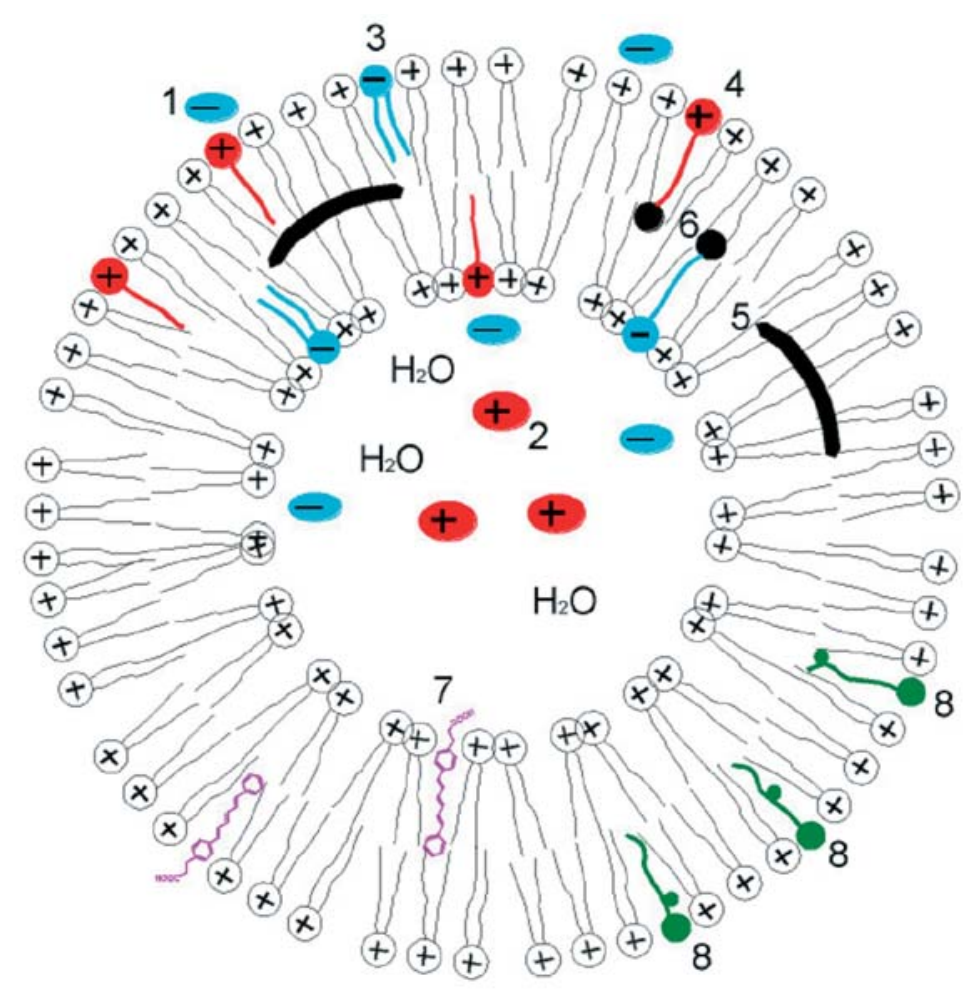

Figura 6 Lipossoma composto por surfactantes catiónicos e interacções possíveis de vários tipos de compostos: 1. composto aniónico, 2. composto catiónico, 3. surfactante aniónico incluído, 4. composto catiónico possuindo uma parte apolar, 5. composto lipofílico, 6. composto aniónico possuindo uma parte apolar, 7. DPH-PA, 8. sondas fluorescentes (n-AS) 


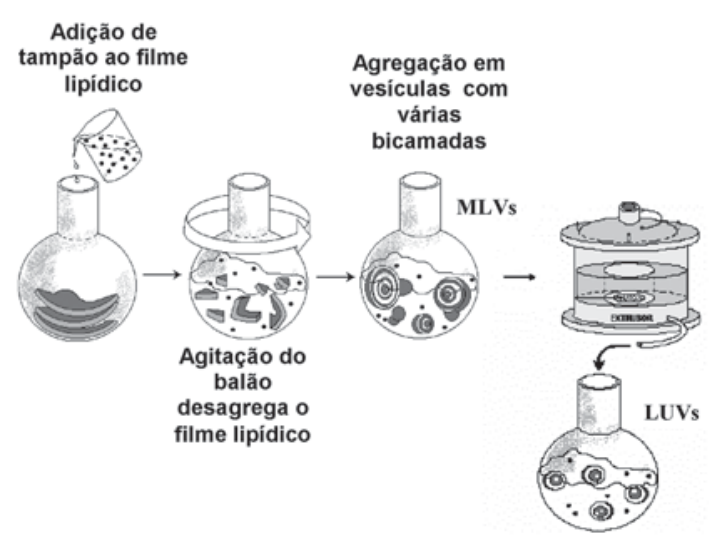

Figura 7 Preparação de lipossomas gânico. O fosfato é depois convertido em ácido fosfomolíbdico por adição de uma solução de molibdato de amónio e posteriormente reduzido pelo reagente de Fiske \& Subbarrow a azul de molibdénio. A intensidade da cor azul das soluções é, então, medida espectrofotometricamente.

\section{Caracterização dos lipossomas}

As características físicas e químicas dos lipossomas, tais como o tamanho, número de lamelas, potencial de membrana e estabilidade são dependentes da composição e do método utilizado na sua preparação, pelo que é importante proceder à sua caracterização.

Determinação do diâmetro dos lipossomas - A granulometria dos lipossomas, assim como a sua homogeneidade, pode ser determinada por espectroscopia de correlação fotónica. Segundo este método, os diâmetros são determinados através da medição da dispersão pro-

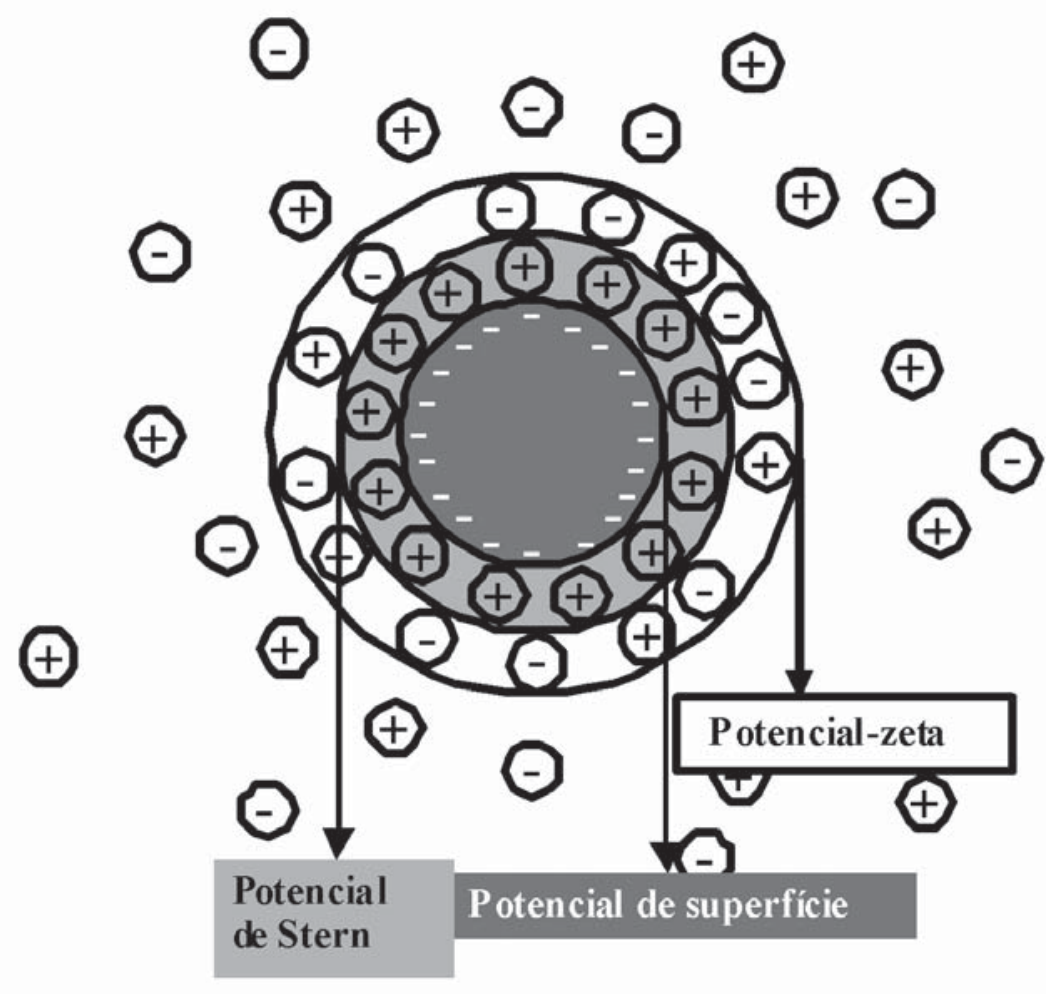

Figura 8 Representação esquemática da dupla camada de cargas à superfície de uma partícula aniónica (membrana biológica, modelos de membrana) vocada numa radiação laser incidente por parte das vesículas em suspensão. Uma vez que estas não são estáticas, a difracção da luz ao longo do tempo varia em função do coeficiente de difusão (D) do meio de dispersão. Assim, as variações da intensidade da difracção da luz são tanto mais rápidas quanto menores forem as vesículas em suspensão. O coeficiente de difusão (D) pode ser determinado analisando dados a diferentes tempos de amostragem. A partir destes dados e, juntamente com os da temperatura absoluta $(T)$ e da viscosidade do meio $(\mu)$, é possível determinar o raio hidrodinâmico (R) das vesículas, através da equação de Stokes-Einstein:

\section{$\mathrm{D}=\mathrm{KT} / 6 \pi \mu \mathrm{R}$}

em que K é a constante de Boltzmann.

Como os lipossomas obtidos por hidratação do filme lipídico (MLV) constituem uma população irregular e polidispersa, cujo tamanho pode variar entre alguns nanómetros a vários micrómetros, constituídos na sua maioria por várias camadas de fosfolípidos concêntricas e aglomerados de vesículas, havendo também fosfolípidos não incluídos nas membranas [4] o seu diâmetro é difícil de medir por espectroscopia de correlação fotónica. Os LUV são o tipo de amostra que proporciona bons resultados com esta técnica de determinação de raio de partículas, devido à sua homogeneidade de tamanhos e à sua esfericidade, sendo a espectroscopia de correlação fotónica uma técnica muito difundida para análise destas vesículas [7].

Determinação do potencial-zeta dos lipossomas - Outros métodos de caracterização dos lipossomas baseiam-se na determinação do potencial-zeta a partir do qual se obtém informação acerca do potencial de membrana das vesículas lipossómicas. O potencial de superfície dos lipossomas pode ser determinado usando o mesmo equipamento descrito no estudo da granulometria. Este estudo baseia-se na medição da mobilidade electroforética das vesículas fosfolipídicas, a partir da qual é possível calcular o potencial-zeta (Figura 8).

Para a medição da mobilidade electroforética recorre-se à utilização de uma célula munida de dois eléctrodos que criam 
uma diferença de potencial, na qual se movimentam as partículas em suspensão. A velocidade de deslocamento das partículas depende da respectiva carga (Figura 9). A medição efectuada por este equipamento é baseada no efeito de Doppler ("Laser Doppler Electrophoresis"), ou seja, na alteração da frequência sofrida pela luz dispersa por uma partícula em movimento. Como a frequência da luz é demasiado elevada, a alteração desta, pode ser medida recorrendo ao uso de barras de interferência causadas pelo cruzamento de dois raios laser originados de uma mesma fonte. Assim, as partículas em movimento interagem com as barras, causando a dispersão da luz que é medida por um fotomultiplicador focado para o ponto de confluência dos lasers. A contagem dos fotões permite a elaboração de um espectro de frequência, a partir do qual o potencial-zeta das partículas pode ser calculado.

Verificação da estabilidade dos lipossomas - Os lipossomas podem sofrer agregação, fusão e ruptura membranar, com o decorrer do tempo e dependendo da constituição lipídica, bem como do meio envolvente. A verificação da estabilidade física dos lipossomas pode efectuar-se através da avaliação do diâmetro médio das vesículas ao longo do tempo.

Estudos realizados com diversas amostras de lipossomas (MLVs e LUVs) guardadas ao longo de vários dias a $4^{\circ} \mathrm{C}$ e a $25^{\circ} \mathrm{C}$, permitiram verificar que os MLVs são pouco estáveis, sofrendo rapidamente (ao fim de 3 dias) alteração por aglomeração, originando aumento no diâmetro médio das partículas. Por sua vez, os LUVs são muito estáveis fisicamente: quando mantidos à temperatura de $4^{\circ} \mathrm{C}$ não apresentam alteração do diâmetro médio ao fim de 5 dias; quando armazenados à temperatura ambiente apresentam aumento de diâmetro médio de $10 \%$ ao fim do mesmo tempo.

Quimicamente, os fosfolípidos que constituem os lipossomas podem sofrer dois grandes processos degenerativos: hidrólise e oxidação [4]. A oxidação dos fosfolípidos acontece preferencialmente com os fosfolípidos poli-insaturados, como é o caso da fosfatidilcolina. Essa oxidação dá-se, na ausência de oxidantes específicos, via um mecanismo de

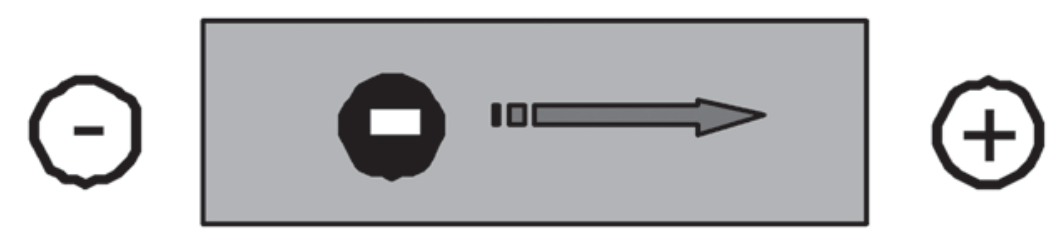

Figura 9 Representação esquemática de uma célula pertencente ao equipamento de espectroscopia de correlação fotónica com dois eléctrodos e uma amostra de um lipossoma carregado negativamente

radicais livres. A presença de oxigénio, luz e elevadas temperaturas intensifica o processo, pelo que é importante a protecção dos lipossomas contra estes factores. Os produtos da degeneração lipídica podem ser detectados experimentalmente através de diversas metodologias descritas na literatura [8-10].

\section{Metodologias usadas na avaliação das interacções fármaco/membrana}

A acção dos fármacos divide-se geralmente em duas fases: fase farmacocinética e fase farmacodinâmica. A primeira compreende os processos de absorção, distribuição, metabolismo e eliminação. A fase farmacodinâmica inclui os processos biológicos envolvidos na interacção dos fármacos com os seus alvos de acção (receptores, enzimas, etc). Antes de exercer o seu efeito e para que seja produzida uma resposta terapêutica, os fármacos têm que atravessar as membranas e atingir os locais alvo numa concentração suficiente para permitir actividade biológica. Com efeito, resultados obtidos em diversos estudos permitem apontar para a hipótese de que a interacção não específica de certos fármacos com a membrana faz parte do seu processo de acção, por permitir que os fármacos atinjam receptores proteicos específicos.

Neste sentido é evidente a importância quer da extensão da interacção fármaco/membrana lipídica, fenómeno quantificado pelo coeficiente de partição (Kp) [11], quer a localização adequada do fármaco na membrana [12]. Valores de Kp elevados (>100) aumentam a probabilidade de o fármaco interagir com o receptor por uma via transmembranar ou a possibilidade de penetrar a uma profundidade adequada na membrana lipídica, de modo a que se possa difundir até ao local activo. A orientação com que o fármaco se localiza na membrana é também crucial, uma vez que deverá interactuar na posição adequada com o local activo do receptor.

Para além de estudos de partição e localização, é ainda fundamental, que a interacção de fármacos com as membranas, seja avaliada pela determinação do potencial de membrana [13]. De facto, as membranas celulares apresentam carga, devida à presença de componentes ionizados (lípidos, glicolípidos e glicoproteínas) na sua constituição. A interacção dos fármacos com as membranas e a consequente alteração do potencial de superfície resultante pode afectar diversos processos regulatórios, nomeadamente a condução de estímulos eléctricos, assim como, a conformação e actividade de enzimas membranares [14, 15]. Neste contexto, além deste estudo permitir a quantificação de fármacos possuidores de carga eléctrica ligado à membrana, também possibilita a caracterização das propriedades electrostáticas da membrana induzidas por essa ligação, a qual constitui um parâmetro fundamental dada a relevância biológica das propriedades de superfície da bicamada lipídica.

Para além dos aspectos químicos da interacção dos fármacos com as membranas biológicas é também necessário atender aos aspectos físicos dessa interacção. As membranas biológicas exibem uma estrutura global comum, altamente dinâmica e fluida com as moléculas de fosfolípidos orientadas de modo a formar uma dupla camada na qual se inserem as proteínas membranares. Os lípidos nas membranas das células à temperatura corporal estão no estado fluido o que permite movimentos laterais. A microviscosidade em cada fo- 
Iheto da bicamada lipídica pode assim determinar o grau de penetração e a taxa de difusão lateral de proteínas da membrana. Deste modo, a região hidrocarbonada da bicamada lipídica pode ter um papel significante determinando interacções de proteína-lípido além de apenas constituir a matriz hidrofóbica na qual proteínas de membrana se inserem. Assim, qualquer modificação da estrutura lipídica da membrana alterará as propriedades da membrana e poderá afectar o funcionamento da célula. Os fármacos capazes de provocar alterações na fluidez da membrana poderão ser responsáveis por mudanças nas propriedades catalíticas observadas em enzimas ligadas à membrana [16] .

A estrutura da membrana parece então ser importante não só para as características de permeabilidade da membrana e interacção de moléculas exógenas, como também para a acção de moléculas endógenas acopladas à membrana (proteínas, receptores, canais) e nos mecanismos moleculares envolvidos nos efeitos farmacológicos exibidos por uma variedade de fármacos, pelo que é fundamental a avaliação dos efeitos dos fármacos na fluidez da membrana.

Os lipossomas devido à sua semelhança estrutural com as membranas celulares têm demonstrado fornecer uma boa correlação relativamente à interacção de fármacos com biomembranas possibilitando realizar vários e diferentes estudos sem a complexidade verificada nos ensaios in vivo e com a aplicação de metodologias analíticas simples descritas seguidamente.

Quantificação da interacção do fármaco com a membrana - A lipofilia dos fármacos tem sido, desde há muito tempo, associada a fenómenos biológicos, como o transporte através de membranas, aos efeitos tóxicos e terapêuticos apresentados e a fenómenos de bioacumulação em tecidos. O parâmetro mais largamente usado para descrever a lipofilia de um composto é o coeficiente de partição octanol/água ( $\left.\mathrm{K}_{0 / a}\right)$ que corresponde à razão entre a concentração na fase orgânica e a concentração na fase aquosa ${ }^{1}$. No entanto, enquanto que para fármacos relativamente hidrofóbicos este modelo mimetiza razoavelmente a partição solvente-membrana, para substâncias com grupos polares nem sempre se obtém uma boa correlação. Isto porque as membranas biológicas, constituídas por uma bicamada de fosfolípidos, apresentam uma zona interna de natureza apolar e duas zonas externas de natureza polar, pelo que as interacções das membranas com os fármacos são mais complexas do que é sugerido pelo modelo simplista de cálculo do $\mathrm{K}_{\mathrm{o} / \mathrm{a}}$. Os lipossomas e as micelas têm vindo a substituir vantajosamente os sistemas octanol/água, devido principalmente ao seu arranjo molecular ordenado, semelhante ao das membranas naturais, mas também pela possibilidade de estudar as influências electrostáticas durante os fenómenos de partição. Assim, a determinação do coeficiente de partição lipossomas ou micelas/água (Kp) fornece indicações mais fiáveis sobre o grau de interacção de um fármaco com as biomembranas sendo estes modelos biomiméticos capazes de mimetizar os variados ambientes membranares, desde a superfície polarizada até ao seu interior lipofílico. Por outro lado, o facto do n-octanol ser relativamente tóxico e poluidor (duas vertentes opostas à ideia de química verde) ditam a sua cada vez maior inaplicabilidade neste tipo de estudos.

A determinação experimental do valor do $\mathrm{Kp} \mathrm{em} \mathrm{modelos} \mathrm{membranares} \mathrm{pode}$ ser efectuada com base em dois tipos de técnicas distintas. No primeiro grupo incluem-se métodos que recorrem a uma separação de fases, envolvendo por exemplo, processos de filtração, de centrifugação e de diálise, seguidos da determinação quantitativa do soluto numa e noutra fase por técnicas habitualmente usadas em análise quantitativa como a absorção de UV/Vis, fluorescência ou outros. O segundo grupo engloba as metodologias que não recorrem à separação de fases. Neste conjunto de métodos a determinação do coeficiente de partição é efectuada directamente nas soluções, nas quais o soluto na mem- brana se encontra em equilíbrio com o soluto livre em solução. A vantagem destes métodos é que a medida é efectuada sem alteração das condições de equilíbrio. A determinação do Kp é efectuada por avaliação da modificação das propriedades de um dos componentes do sistema: a) propriedades do soluto após interacção com o lípido tais como as suas propriedades espectroscópicas ou características ácido/base de acidez, b) propriedades do lípido por acção do soluto, como a permeabilidade, fluidez, tensão superficial, temperatura de transição de fase, carga superficial, entre outras, c) ou, finalmente, de uma propriedade de uma terceira molécula que pode ser incorporada no sistema e funcionar como sonda e cuja variação das propriedades em função da interacção molecular é usada para avaliar a extensão da interacção.

Dos métodos apresentados para a determinação de Kp serão apenas descritos aqueles que se baseiam em procedimentos analíticos simples e comuns em qualquer laboratório e que englobam a determinação do Kp por espectrofotometria derivativa; por desactivação de fluorescência e por determinação do potencial-zeta.

A determinação do $\mathrm{Kp}$ usando a espectrofotometria UV-Vis baseia-se na variação das características espectrais (absortividade molar e/ou comprimento de onda de absorção máximo, $\lambda$ máx) do soluto, quando este se localiza em meios com características polares distintas [11]. O recurso à espectrofotometria UV-Vis apresenta bastantes vantagens, pois não só a maioria dos compostos possui propriedades espectroscópicas facilmente mensuráveis, que dependem da natureza química do meio e são proporcionais à concentração do composto em cada uma das fases, como, por outro lado, a sua sensibilidade permite o uso de concentrações semelhantes às encontradas em sistemas naturais. No entanto, especialmente no caso do uso de lipossomas como modelos membranares, a presença de estruturas micro-heterogéneas de tamanhos não

\footnotetext{
1 O coeficiente de partição é definido pela IUPAC em termos de actividades e a correspondência para concentrações é denominada por razão de partição, mas dada a prática comum em literatura biológica do coeficiente de partição, neste artigo adoptou-se esta nomenclatura.
} 
negligenciáveis causa dispersão da luz, principalmente a comprimentos de onda inferiores a $300 \mathrm{~nm}$ o que resulta na diminuição da quantidade de luz que atinge o detector. Estas interferências espectroscópicas, bem como a absorvância das próprias microestruturas, dificultam grandemente a análise das variações da absorvância do soluto. A subtracção de um branco é sempre uma primeira operação para reduzir este efeito, no entanto ele só é geralmente eliminado após a aplicação da segunda derivada aos sinais registados. Neste contexto, os métodos de espectrofotometria derivativa apresentam vantagens pois permitem a eliminação de interferências causadas pelos sistemas organizados, difíceis de anular em espectrofotometria de ordem zero, sem a necessidade de se recorrer a técnicas de separação de fases. As medidas são, assim, efectuadas sem interferência nos equilíbrios estabelecidos obtendo-se uma melhor resolução das bandas sobrepostas e a eliminação de interferências espectrais (dispersão de luz).

Atendendo à definição de constante de partição e nas condições em que é válida a lei de Lambert-Beer, a absorvância de uma solução contendo uma determinada concentração de fármaco (Abs) que é partilhado entre as fases membra- nar (m) e aquosa (a) pode relacionar-se com Kp segundo a equação (2):

$$
\mathrm{Abs}_{\mathrm{T}}=\mathrm{Abs}_{\mathrm{a}}+\frac{\left(\mathrm{Abs}_{\mathrm{m}}-\mathrm{Abs}_{\mathrm{a}}\right) \mathrm{K}_{\mathrm{p}}[\mathrm{L}] \mathrm{V}_{\varphi}}{1+\mathrm{K}_{\mathrm{p}}[\mathrm{L}] \mathrm{V} \varphi}
$$

sendo Abst, Abs $\mathrm{m}$ e Abs a a absorvância do composto total, em lípido e em água, respectivamente; $\mathrm{Kp} \mathrm{o}$ coeficiente de partição, [L] a concentração lipídica e $\vee \varphi$ o volume molar lipídico.

Tal como as absorvâncias, também as intensidades obtidas após derivação dos espectros são proporcionais à concentração de fármaco, desde que os fenómenos de dispersão de luz sejam eliminados. Como tal, uma expressão formalmente idêntica pode ser usada para a determinação do Kp após a derivação dos espectros, substituindo Abs pela sua derivada $D=\left(d^{n} A b s\right) /\left(d \lambda^{n}\right)$ [17- 19].

Assim, na prática para a determinação do Kp de um fármaco num sistema modelo membranar/água por espectrofotometria derivativa, procede-se à leitura de absorvâncias de uma dada solução de fármaco de concentração conhecida em diversas suspensões lipídicas de concentrações crescentes (Figura 10A). Após subtracção das absorvâncias de soluções de brancos com concentrações lipídicas idênticas procede-se ao cálculo da derivada (Figura 10B). Representando graficamente as absorvâncias máximas obtidas no espectro da derivada (onde as interferências espectrais são totalmente eliminadas - Figura 11) em função das concentrações do lípido utilizado e ajustando a equação (2) a estes valores experimentais, obtém-se uma regressão não linear cujo parâmetro Kp pode ser calculado (Figura 10C).

A desactivação de fluorescência ("quenching") é outro método que permite caracterizar quantitativamente a interacção fármaco/membrana. Neste caso, a determinação do coeficiente de partição recorre às propriedades fluorescentes de uma terceira molécula, sonda, que é incorporada no sistema. O uso de moléculas lipofílicas que apresentam uma elevada intensidade de fluorescência, permite, no caso de interacção entre a sonda fluorescente (fluoróforo) e o soluto em análise (fármaco), quantificar o soluto presente no meio lipídico. Para cada uma das concentrações de lípido faz-se variar as concentrações do fármaco e com base na equação de Stern-Volmer [19], ajustando-se graficamente os valores das intensidades de fluorescência em função da concentração de fármaco, obtêm-se relações lineares em que a ordenada na origem é igual a zero
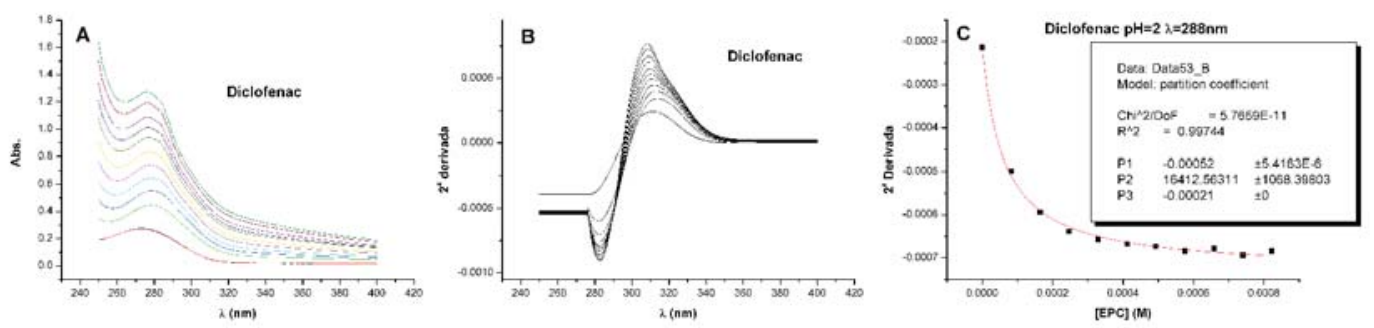

Figura 10 A. Espectros de UV/Vis do diclofenac com concentrações crescentes de lípido. B. Segunda derivada dos espectros após subtracção de brancos. C. Ajuste da curva teórica aos pontos experimentais com determinação do Kp
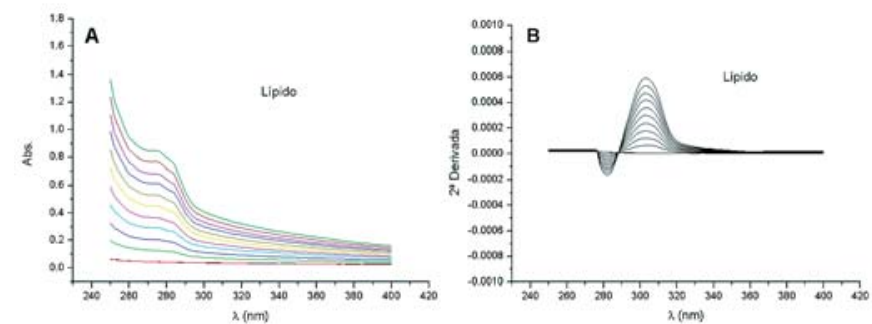

Figura 11 A Espectros de UV/Vis de concentrações crescentes de lípido. B. Segunda derivada de A 
e o declive igual à constante aparente de Stern-Volmer ( $\left.\mathrm{K}_{\mathrm{Sv}}^{\mathrm{app}}\right)$.

Os valores de $\mathrm{K}_{\mathrm{sv}}^{\mathrm{app}}$ dependem não só da eficácia de desactivação de fluorescência pela presença do fármaco desactivador, mas também do coeficiente de partição (Kp) entre as fases aquosa e lipídica, e esta dependência é descrita pela equação (3):

$$
\mathrm{K}_{\mathrm{sv}}^{\mathrm{app}}=\mathrm{K}_{\mathrm{sv}} \frac{\mathrm{K}_{\mathrm{p}}}{\mathrm{K}_{\mathrm{p}} \mathrm{V}_{\mathrm{m}}+1}
$$

Sendo $\mathrm{K}_{\mathrm{sv}}$ a constante de Stern-Volmer e $V_{m}$ o volume molar de lípido (relacionado com a concentração lipídica).

Através da equação (3), representando os valores de $\mathrm{K}_{\mathrm{Sv}}^{\mathrm{app}}$ obtidos para as diferentes concentrações de lípido em função de $V_{m}$ obtém-se um gráfico que por ajuste não linear permite determinar o Kp [17-19].

No caso do estudo da partição de fármacos ionizáveis com a membrana, um factor importante deve ser tomado em consideração: o equilíbrio de ionização do fármaco a determinado valor de $\mathrm{pH}$. Compostos que se encontram ionizados ao $\mathrm{pH}$ de trabalho, geram cargas à superfície das membranas quando as partilham. Este potencial (zeta) pode ser determinado a diferentes concentrações de fármaco para avaliar o coeficiente de partição do composto na membrana. Este método extensivamente descrito por Matos et al. [13], sendo menos intuitivo que os dos dois outros supracitados, não será aqui desenvolvido.

Localização do fármaco na membrana - O conhecimento da localização membranar dos fármacos e a sua orientação possui grande importância, especialmente quando estes actuam directamente nas membranas ou interactuam com moléculas aí localizadas, tais como enzimas ou receptores. Este estudo permite assim, um conhecimento mais aprofundado do modo de acção dos fármacos, contribuindo para o desenvolvimento de novas formas farmacêuticas mais potentes, mais selectivas e detentoras de menores efeitos secundários.

A localização membranar dos fármacos pode efectuar-se, fundamentalmente, através de dois tipos de métodos distin-

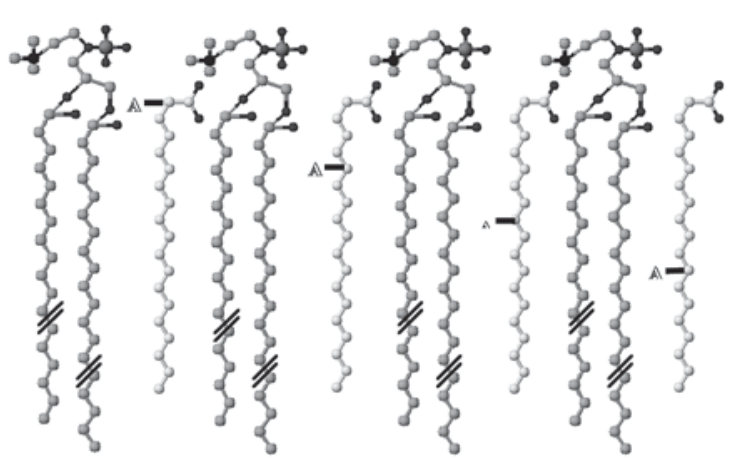

A

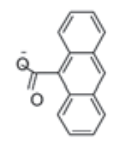

Figura 12 Estrutura química das sondas $\mathrm{n}$-AS ( $\mathrm{n}=2,6,9$ e 12) e sua localização na membrana. (A) corresponde ao grupo antracénico

tos: directos e indirectos. Nos métodos directos a localização é avaliada por técnicas como a difracção de raios- $X$ RMN, entre outros. Nos métodos indirectos, mede-se uma determinada propriedade que depois é relacionada com a localização dos solutos, por exemplo, propriedades de sondas de localização membranar conhecida, cuja alteração diferencial por acção do fármaco permite inferir acerca da localização deste na membrana.

Um método indirecto muito usado em estudos de localização em modelos membranares, membranas naturais e células, é a desactivação de fluores-

cência. Esta metodologia baseia-se no conhecimento rigoroso da localização das sondas (fluoróforos) na membrana lipídica. A fluorescência emitida por um determinado fluoróforo contém informações relacionadas não apenas com o fluoróforo, mas também acerca das moléculas que o rodeiam. 0 fundamento do método de desactivação de fluorescência em estruturas organizadas envolve assim um fluoróforo solubilizado no interior da estrutura ou adsorvido à sua superfície, cuja fluorescência é desactivada pela presença do soluto (fármaco) que pode estar partilhado entre a fase organizada e o solvente. A velocidade e/ou extensão com que o fármaco penetra na estrutura, bem como a velocidade de difusão do fluoróforo vão determinar a cinética do processo de desactivação, sendo que a extensão da desactivação de fluorescência é inversamente proporcional à distância entre o fluoróforo e o fármaco desactivador.
Uma indicação de quão profundamente o fármaco se situa na bicamada lipídica, pode ser fornecida pela comparação da eficácia de desactivação da fluorescência de uma série de sondas estruturalmente semelhantes, contendo o mesmo grupo fluorescente ligado a diferentes posições de um esqueleto hidrocarbonado ácido (+) -n-(9-antroiloxi)- esteárico (n-AS), $n=2,6$, 9 e 12 (Figura 12). As sondas $n$-AS (a cinza claro na figura) inserem-se na membrana com a cadeia estearoil paralela às cadeias de fosfolípidos (representadas a cinza escuro), e o grupo antracénico perpendicular ao plano da membrana, localizando-se a sonda 2-AS perto da parte polar da bicamada, a 12-AS mais profundamente e as restantes sondas em posição intermédia. Como a desactivação de fluorescência requer um contacto próximo entre o fluoróforo e o desactivador, a eficácia relativa da desactivação das sondas pode ser usada para prever a localização relativa de um fármaco na bicamada lipídica. Assim, se a desactivação da fluorescência pelo fármaco é maior para as sondas 2 e 6-AS, tal sugere que o fármaco possua uma localização mais superficial junto às cabeças polares da membrana. Se o oposto se verifica e o fármaco provoca uma desactivação mais forte para as sondas 9 e 12-AS então tudo indica que o fármaco terá uma localização mais profunda junto às cadeias hidrocarbonadas apolares da bicamada.

Modificação da fluidez e permeabilidade da membrana - As biomembranas exibem uma estrutura altamente dinâmica e fluida, a qual permite a preservação de 
todas as suas funções biológicas. No entanto, a interacção de moléculas com as membranas pode induzir perturbações no seu estado físico. Estas modificações podem ser observadas por estudos de fluidez da membrana, os quais mostraram ser importantes para o esclarecimento quer de mecanismos biológicos quer de condições patológicas, como inflamação crónica, cancro e doenças cardiovasculares [16, 20-26]. Adicionalmente, tem sido sugerida uma relação entre a capacidade dos fármacos em alterarem a fluidez da membrana e a sua actividade antioxidante [26-28].

A fluidez da membrana pode ser avaliada por diferentes métodos, como calorimetria diferencial (differential scanning calorimetry), anisotropia de fluorescência, polarização generalizada de Laurdan (Laurdan generalized polarization) e estudos de perda da carboxifluoresceína (carboxyfluorescein leakage). Uma das técnicas mais utilizadas para determinar a fluidez membranar é a calorimetria diferencial, dado não necessitar de sondas. No entanto, a técnica mais largamente utilizada é a anisotropia de fluorescência "steady-state", uma vez que os fluorimetros são actualmente instrumentos muito mais comuns nos laboratórios que os calorímetros.De facto, existem numerosos estudos na literatura científica acerca da influência dos fármacos na fluidez membranar por determinações de anisotropia de fluorescência.

A anisotropia de fluorescência fundamenta-se na determinação do grau e da extensão da rotação difusional do fluoróforo (sonda) durante o tempo de vida do estado excitado. Pequenas alterações na rigidez da matriz envolvente da sonda, produzem alterações no movimento rotacional da sonda e, como tal, provocam alterações na anisotropia.

Os estudos com sondas de fluorescência para avaliar as propriedades físicas das membranas sintéticas e biológicas apresentam algumas vantagens relativamente a outras técnicas: a) permitem obter informação sobre a polaridade e microviscosidade da matriz em estudo, b) existe uma variedade de sondas diferentes que permitem monitorizar regiões específicas da membrana, e c) as son- das podem ser usadas em baixas concentrações, minimizando as perturbações que possam ocorrer na membrana por inclusão da sonda [29-31]. Como tal, os estudos de anisotropia com sondas fluorescentes têm sido amplamente usados para avaliar a fluidez da membrana [30]. A validade deste parâmetro tem sido, no entanto, questionada. As sondas de fluorescência permitem avaliar qualitativamente as alterações globais da fluidez da bicamada, mas é aconseIhável algum cuidado na interpretação directa dos resultados experimentais, uma vez que alterações na fluidez devidas a agentes que as perturbem não são uniformes em todos os segmentos das cadeias de ácidos gordos e a própria sonda pode ter influência nos resultados obtidos. De forma a poder interpretar claramente os resultados experimentais obtidos é necessário considerar correcções apropriadas aos dados experimentais e definir algumas condições para o estudo. Primeiro, as sondas de fluorescência usadas devem possuir um comportamento ao nível da emissão bem caracterizado e o seu local de solubilização (ou afinidade da sonda para uma determinada localização na membrana) ser conhecido com alguma certeza (sondas da série $n$-AS, DPH), para que as alterações de anisotropia detectadas sejam resultado de uma verdadeira alteração da estrutura da membrana e não de uma mera alteração da posição da sonda [32]. Assim, a escolha do fluoróforo deverá recair sobre sondas largamente descritas e estudadas tais como as sondas n-AS, ou qualquer outra série de sondas estruturalmente semelhante com o mesmo grupo fluorescente posicionado a diferentes profundidades na bicamada (Figura 12), possibilitando o estudo do "gradiente de fluidez" em modelos membranares ou biomembranas [33]. Outra dificuldade encontrada no estudo da fluidez por esta metodologia, é o impedimento dos movimentos rotacionais das sondas quando estas estão inseridas nas membranas. Isto porque, o ambiente anisotrópico das membranas impede a livre rotação do fluoróforo e a anisotropia decai para um valor finito, não podendo a despolarização ser descrita como em meios isotrópicos e homogéneos. No entanto, este problema pode ser ultrapassado, já que estudos prévios nas membranas mostraram que sob certas condições, como a selecção de um comprimento de onda de excitação adequado e o uso de temperaturas em que a membrana esteja na fase fluida [34], é possível obter uma rotação das sondas praticamente desimpedida.

Finalmente, para além da limitação na rotação da sonda existente num meio anisotrópico há também o problema dos resultados experimentais poderem ser influenciados pela própria sonda. Com efeito, é possível que as alterações de anisotropia observadas sejam causadas não só por alterações na microviscosidade da membrana, mas também por variações no tempo de vida do estado excitado do fluoróforo [34]. Para evitar interpretações ambíguas, é necessário considerar correcções apropriadas aos dados experimentais e as medidas de anisotropia devem ser corrigidas para a variação do tempo de vida do estado excitado do fluoróforo $[35,36]$.

Efeitos dos fármacos no potencial de superfície da membrana - Como já foi referido anteriormente, dada a relevância biológica das propriedades da superfície da membrana lipídica, nomeadamente das suas propriedades electrostáticas, evidenciada em estudos de condução de estímulos eléctricos, de funcionamento de enzimas e de integridade estrutural dos componentes da membrana [14, 15], é desejável obter uma compreensão quantitativa dessas propriedades, e de como elas são influenciadas pela ligação dos fármacos. Assim, a combinação do coeficiente de partição e constantes de acidez para estabelecer possíveis contribuições electrostáticas da interacção de fármacos com lipossomas ou micelas constitui uma útil abordagem nos estudos das interacções dos fármacos com as membranas (Figura 13).

Com efeito, alguns fármacos, alteram significativamente o estado eléctrico da membrana, podendo esta alteração acarretar diferenças no comportamento das membranas in vivo quanto a fenómenos de permeabilidade, condução de estímulos, como a dor, ou alteração da actividade de enzimas ligadas à membrana. Estas alterações podem trazer consequências ao nível da acção 


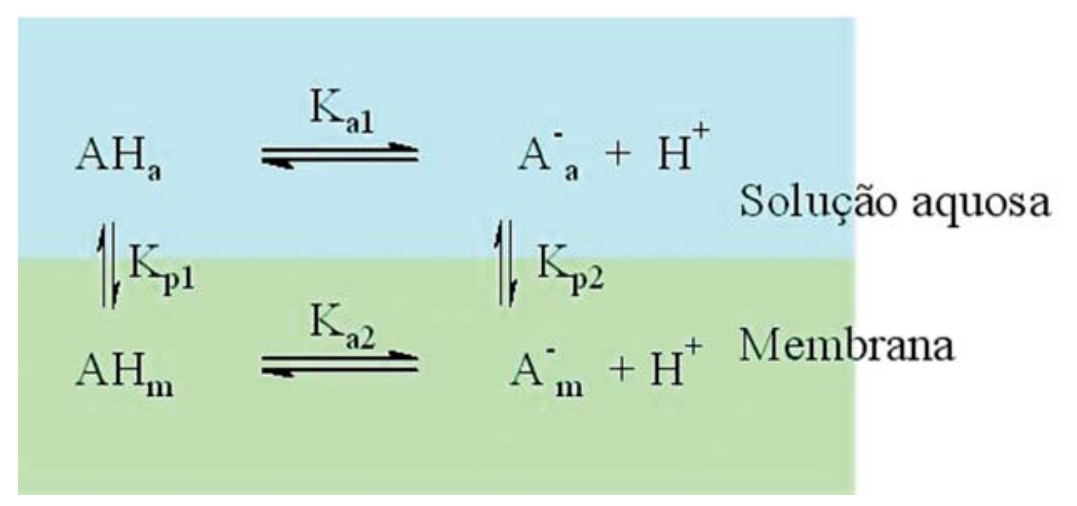

Figura 13 Esquema da partição solução aquosa/membrana de um fármaco com características de ácido fraco (AH)

dos fármacos, podendo explicar, pelos menos parcialmente, os seus efeitos ao nível da fisiologia da dor e da inflamação. Pode compreender-se assim, que as alterações eléctricas consequentes da ligação do fármaco à membrana poderão conduzir à inibição de determinados processos referentes à sua actividade terapêutica, e à indução de outros, como os efeitos colaterais.

A actividade biológica dos fármacos é então muitas vezes condicionada pelas suas propriedades ácido-base, já que o grau de ionização das moléculas está intimamente ligado à lipossolubilidade [37]. Dependendo do carácter hidrolipofílico dos fármacos, estes podem estar distribuídos em maior ou menor extensão entre a membrana e a fase aquosa. Essa distribuição condiciona a concentração dos mesmos em cada fase, e controla a sua penetração na membrana e/ou as suas interacções com os fosfolípidos ou outros componentes membranares [20].

Por estudos de microelectroforese, pode ser determinado o efeito dos fármacos nas propriedades electrostáticas de lipossomas. É de prever que um fármaco que exista predominantemente na forma neutra em determinado $\mathrm{pH}$, não altere o potencial de membrana nesse mesmo valor de $\mathrm{pH}[17,18]$. Pelo contrário, a interacção de moléculas de fármaco, carregadas negativamente, com a membrana lipídica, vai conferir um potencial de superfície mais negativo à membrana. Em alguns dos estudos realizados, verifica-se que os valores de potencial-zeta de lipossomas de EPC obtidos decrescem à medida que a concentração de fármaco aumenta na fase aquosa, e mais fármaco está disponível para estabelecer a interacção [13, 18, 19]. O conhecimento das propriedades ácido-base e da hidrofobicidade dos fármacos permitem, então, descrever o efeito da ligação destes nas propriedades eléctricas da bicamada fosfolipídica e com isto fornecem mais uma pista para a compreensão do seu mecanismo de acção e efeitos adversos.

Efeito dos fármacos na estabilidade dos fosfolípidos membranares - Um dos paradoxos da vida neste planeta é que a molécula que sustenta a vida aeróbia, o oxigénio, não só é fundamentalmente essencial para o metabolismo e respiração, como é também implicado em muitas doenças e condições degenerativas. Um elemento comum em desordens humanas tão diversas como envelhecimento, artrite, cancro e muitas outras é o envolvimento de formas parcialmente reduzidas de oxigénio- os radicais livres. Os radicais livres são espécies químicas extremamente reactivas que podem induzir uma grande variedade de danos ao nível celular, por exemplo, podem inactivar a síntese de DNA ou danificar as biomembranas atacando as proteínas envolvidas no transporte de iões ou induzindo alterações na sua composição e propriedades físicas. Com efeito, um dos componentes da célula que é particularmente susceptível ao ataque oxidativo é a membrana, devido à presença de lípidos que contêm ácidos gordos poli-insaturados e que podem ser prontamente peroxidados através do ataque às ligações duplas dos fosfolípidos com resultante aumento da rigidez da mem- brana e, muitas vezes, morte celular [24].

Antioxidantes que ajudam as células a resistir ao stress oxidativo pela sua capacidade de extinguir efectivamente os radicais livres de oxigénio e azoto (ROS/RNS), têm sido associados à prevenção de doenças. Há por isso uma necessidade crescente de saber a capacidade antioxidante de fármacos, com vista a utilizá-los na terapia de doenças como o cancro. Os fármacos presentes nas membranas (ou extra-membranares) podem actuar contra o processo de oxidação (os antioxidantes) ou estimulá-lo (os pro-oxidantes). Alguns investigadores recorrem à modelização de estruturas membranares para estudar a oxidação dos fosfolípidos dos sistemas biológicos e a acção antioxidante dos fármacos ou outros compostos. Outros referem o uso de sistemas lipossómicos, mono ou plurilamelares. Efectivamente, o uso de lipossomas, tem mostrado ser o mais apropriado para avaliar os benefícios potenciais de vários antioxidantes em relação à peroxidação lipídica e entender os mecanismos da acção antioxidante. A semelhança entre os lipossomas e a membrana biológica faz dos primeiros uma ferramenta muito útil para investigar a significância das interações antioxidante-lípido de uma forma prática e sem a interferência da presença de antioxidantes naturais da célula que poderiam introduzir dúvidas nos resultados [24].

A avaliação da actividade antioxidante dos fármacos em lipossomas é feita geralmente através de um conjunto de testes de inibição destinados à avaliação da capacidade "scavenger" (de captura) de radicais livres gerados in vitro. Os diversos métodos propostos na literatura variam quanto ao tipo de radicais livres gerados, ao indicador de oxidação escoIhido e ao método usado para a sua detecção e quantificação. Na maioria dos casos recorre-se à formação de radicais instáveis, pela decomposição térmica de azo iniciadores (e.g. ABAP, AMVN, $A A P H)$, os quais reagem rapidamente com o oxigénio originando radicais peroxilo [38, 39]. Estes actuam sobre um substrato lipídico (e.g. ácido linoleíco ou um dos seus ésteres) desencadeando 
um processo de lipoperoxidação, em relação ao qual se escolhe um determinado indicador (e.g. consumo de oxigénio, desaparecimento do substrato lipídico, aparecimento de produtos de oxidação) que se observa e quantifica antes e após a adição de um composto antioxidante (avaliação da actividade "scavenger").

Alguns autores propõem um outro tipo de testes que não recorrem à oxidação de substratos lipídicos, mas à redução de radicais livres estáveis gerados in vitro, como resultado da actividade "scavenger" de compostos antioxidantes. A capacidade "scavenging" de fármacos pode ser determinada espectrofotometricamente pela diminuição da absorvância no visível de radicais tais como o ABTS $^{+}$(ácido 2,2'-azino-bis-(3-etilbenzotiazolina)- 6-sulfonico) e DPPH• (2,2'difenil-1-picrilhidrazilo) [40]. Existem também ensaios conduzidos utilizando uma sonda fluorescente que perderá a sua fluorescência após oxidação por radicais livres [38]. Esta sonda pode-se encontrar dentro da membrana ou fora dessa, no meio aquoso. Quanto maior a capacidade antioxidante de um fármaco, mais lentamente se dará o abaixamento de fluorescência da sonda (Figura 14). O perfil do decréscimo da fluorescência obtido para um determinado composto é geralmente comparado com os resultados obtidos com moléculas aceites como antioxidantes oficiais (trolox, vitamina E). Deste modo, pode ser estabelecida uma escala de poder antioxidante para diferentes compostos de interesse nas condições experimentais utilizadas.

\section{Considerações finais}

Temos vindo a assistir ao desenvolvimento de novas estratégias terapêuticas que proporcionam uma combinação das características farmacocinéticas e farmacodinâmicas dos agentes bioactivos, com vista a maximizar o seu potencial terapêutico e minimizar a sua toxicidade, uma vez que tanto as acções desejáveis como as acções colaterais, na maioria das vezes indesejáveis, estão dependentes da concentração e persistência dos fármacos nos vários compartimentos do organismo. As grandes transformações na área da saúde têm estado ainda associadas ao desenvolvimento de técnicas capazes de permitir um estudo aprofundado do mecanismo de acção dos fármacos. Este último aspecto está intimamente dependente da estrutura química dos fármacos e da sua capacidade de interacção com sistemas biológicos, nomeadamente com as membranas celulares.

Do exposto se depreende a importância do estudo da interacção ao nível molecular, dos fármacos com os lipossomas

Figura 14 Decréscimo da fluorescência de DPH-PA em lipossomas em função do tempo para diferentes concentrações de antioxidante (trolox)

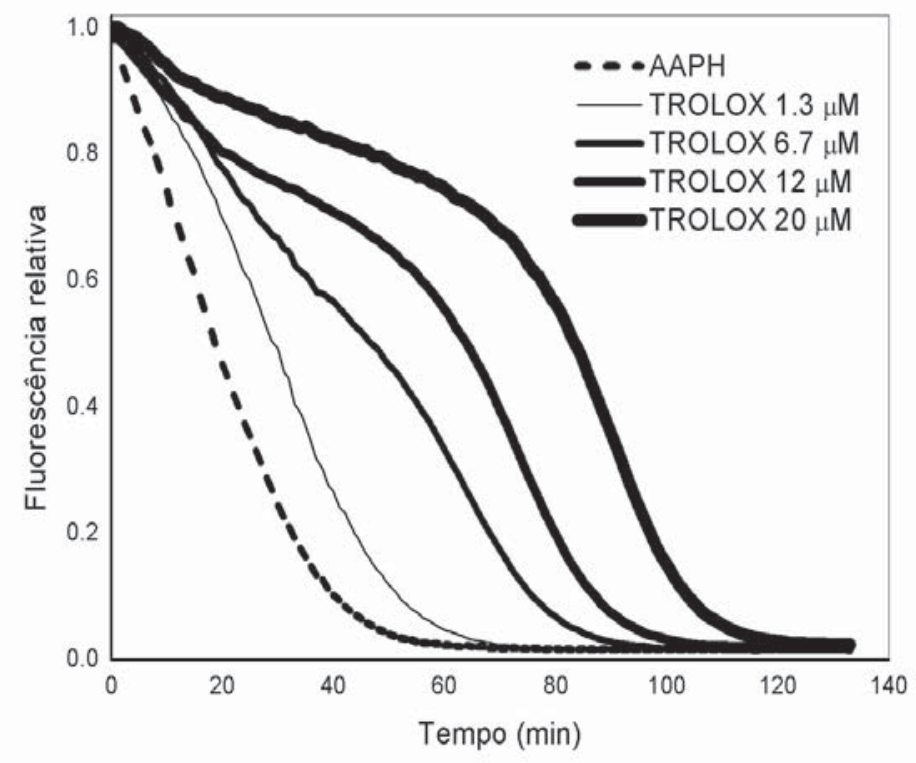

e micelas, determinante para a compreensão dos parâmetros de distribuição dessas moléculas no organismo, bem como para o estabelecimento de relações estrutura-actividade, fundamentais ao desenvolvimento de fármacos cada vez mais eficazes.

Neste contexto pretende-se que este trabalho contribua com a descrição de metodologias analíticas relativamente simples e exequíveis na maioria dos laboratórios, que permitam um conhecimento exaustivo da interacção entre os fármacos e as membranas lipídicas, caracterizada quantitativamente pela determinação de coeficientes de partição e qualitativamente pela elucidação da natureza da referida interacção e da localização dos fármacos nas membranas lipídicas.

\section{Agradecimentos}

Agradece-se à Fundação para a Ciência e Tecnologia (FCT) o suporte financeiro através do projecto POCTI/ FCB/47186/2002 e das bolsas de doutoramento de H.F. (BD 6829/01), de M.L. (BD 21667/99) e de C.S. (SFRH/ $\mathrm{BD} / 7005 / 2001)$.

\section{Referências}

1 M. N. Jones e D. Chapman, Micelles, Monolayers and Biomembranes, WileyLiss Inc., New York, 1995.

2 E. Pramauro e E. Pelizetti, Surfactants in Analytical Chemistry. Applications of Organized Amphiphilic Media, Elsevier, New York, 1996.

3 R. R. New, Liposomes - a practical approach, Oxford University Press, New York, 1990.

4 D. D. Lasic, Liposomes - from Physics to Applications, Elsevier, New York, 1993.

5 B. Jonsson, B. Lindman, K. Holmberg e B. Kronberg, Surfactants and Polymers in Aqueous Solution, John Wiley \& Sons, Chichester, 1998.

6 C. W. F. Mc Clare, Anal. Biochem., 39 (1971) 527.

7 M. T. Montero, I. Carrera e J. Hernández-Borrell, J. Microencapsulation, 11 (1994) 423.

8 R. W. Browne e D. Armstrong, Clin. Chem., 46 (2000) 829. 
9 J. Lang, C. Celotto e H. Esterbauer, Anal. Biochem., 150 (1985) 369.

$10 \mathrm{H}$. Esterbauer e K. H. Cheeseman, Methods Enzymol., 186 (1990) 407.

11 K. Kitamura, N. Imayoshi, T. Goto, H. Shiro, T. Mano e Y. Nakai, Anal. Chim. Acta, 304 (1995) 101.

12 J. R. Lacowicz, Principles of Fluorescence Spectroscopy, 2ed, Kluwer Academic/Plenum Press, New York, 1999.

13 C. Matos, B. Castro, P. Gameiro, J. L. F. C. Lima e S. Reis, Langmuir, 20 (2004) 369.

14 A. J. Russel e A. R. Fersht, Nature, 328 (1987) 496.

15 J. J. Volwerk, P. C. Jost, G. H. de Haas e O. H. Griffith, Biochemistry, 25 (1986) 1726.

16 R. A. Knazek, S. C. Liu, J. R. Dave, R. J. Christy e J. A. Keller, Prostaglandins and Medicine, 6 (1981) 403.

17 H. Ferreira, M. Lucio, B. Castro, P. Gameiro, J. L. F. C. Lima e S. Reis, Anal. Bioanal. Chem., 377 (2003) 293.

18 H. Ferreira, M. Lucio, J. L. F. C. Lima, C. Matos e S. Reis, Anal. Bioanal. Chem., 382 (2005) 1256.

19 H. Ferreira, M. Lucio, J. L. F. C. Lima, C. Matos e S. Reis, J. Pharm. Sci., 94 (2005) 1277.
20 O. Simonetti, G. Ferreti, A. M. Offidani, P. Gervasi, G. Curantola e G. Bossi, Arc. Dermatol. Res., 377 (1996) 293.

21 E. Beccerica, G. Ferretti, G. Curatola e C. Cervini, Pharmcacol. Res., 22 (1990) 277.

22. E. Beccerica, G. Piergiacomi, G. Curatola e G. Ferretti, Pharmacology, 38 (1989) 16

23 H. A. Lehr, J. P. Zimmer, C. Hubner, E. C. Reisinger, A. Kohlschutter e $\mathrm{H}$. Schmitz, J. Antimicrob. Chemother., 28 (1991) 677

24 R. Clarke, H. W. vanden Berg e R. F. Murphy, J. Natl. Cancer Inst., 82 (1990) 1702.

25 G. Taraboletti, L. Perin e B. Bottazzi, Int. J. Cancer, 44 (1989) 707.

26 H. Wiseman, M. Cannon, H. R. V. Arnes tein e D. J. Barlow, Biochim. Biophys. Acta, 1138 (1992) 197.

27 K. L. Horan, B. S. Lutzke, A. R. Cazers, J. M. McCall e D. E. Epps, Free Radic. Biol. Med., 17 (1994) 587.

28 G. Cervato, P. Viani, M. Masserini, C. di Iorio e B. Cestaro, Chem. Phys. Lipids, 49 (1988) 135.

29 M. K. Jain e N. M. Wu, J. Membr. Biol., 34 (1977) 157.
30 M. Shinitzky e Y. Barenholz, Biochim. Biophys. Acta, 515 (1978) 367.

31 B. Lentz, E. Freire e R. L. Biltonen, Biochemistry, 17 (1978) 4475.

32 B. Lentz, Y. Barenholz e T. E. Thompson, Biochemistry, 15 (1976) 4521.

33 K. R. Thulborn e W. H. Sawyer, Biochim. Biophys. Acta, 511 (1978) 125.

34 M. Vincent, B. de Foresta, J. Gallay e A. Alfsen, Biochemistry, 21 (1982) 708.

35 M. Lúcio, H. Ferreira, J. L. F. C. Lima, C. Matos, B. Castro e S. Reis, Phys. Chem. Chem. Phys., 6 (2004) 1493.

36 H. Ferreira, M. Lucio, J. L. F. C. Lima, A. Cordeiro-da-Silva, J. Tavares e S. Reis, Anal. Biochem., 399 (2005) 144.

37 S. Schreier, J. W. A. Frezzatti, P. S. Araújo, H. Chaimovitch e I. M. Cuccovia, Biochim. Biophys. Acta, 769 (1984) 231.

38 A. Arora, M. G. Nair e G. M. Strasburg, Free Radic. Biol. Med., 24 (1998) 1355.

39 F. Castelli, D. Trombetta, A. Tomaino, F. Bonina, G. Romeo, N. Uccella e A. Saija, J. Pharmacol. Toxicol. Methods, 37 (1997) 135.

40 W. Brand-Williams, M. E. Cuvelier e C. Berset, LWT-Food Sci. Technol., 28 (1995) 25.

\section{Nano Surpresa}

Um mecanismo surpreendente através do qual polímeros condicionam a formação de partículas nanométricas pode proporcionar uma nova ferramenta para o controlo do crescimento destes materiais.

As propriedades das nanopartículas dependem criticamente de diversos factores como o tamanho, a distribuição de tamanhos e a morfologia. Por isso, o desenvolvimento de técnicas que possibilitem o controlo do crescimento destas pequenas partículas assume um considerável interesse para os investigadores da área dos materiais.

De acordo com investigadores do Instituto de Tecnologia da Georgia e da Universidade de Drexel, o crescimento de nanopartículas confinada ao interior de uma estrutura de polímero é uma técni- ca vulgar para o controlo dos tamanhos das partículas. Posteriormente, a matriz de polímero é simplesmente removida, e os nanocompósitos resultantes podem ser usados numa grande variedade de aplicações.

No decorrer dos seus trabalhos de investigação, Rina Tannenbaum e os seus colegas constataram uma forte relação entre a reactividade química do polímero e o tamanho e forma das partículas sintetizadas. Por outro lado, a influência nestes parâmetros de outros factores como o peso molecular do polímero ou a temperatura da síntese, revelaram-se relativamente insignificantes.

Os investigadores prepararam nanopartículas de óxido de ferro, usando filmes poliméricos de diferentes tipos, nomeadamente, de poliestireno, polimetilmetacrilato, polisulfona, entre outros. A utilização destes polímeros possibilitou o estudo da natureza e intensidade das interacções entre uma grande variedade de grupos funcionais e as partículas de óxido de ferro. A caracterização das partículas sintetizadas por microscopia electrónica de transmissão, permitiu concluir que o tamanho característico das nanopartículas diminui com uma crescente afinidade ou intensidade da interacção entre o polímero e as partículas de óxido de ferro.

A relação entre o tamanho médio das partículas e a reactividade da interface polimérica pode ajudar outros investigadores na tentativa de controlar o crescimento das nanopartículas através da regulação da reactividade da matriz polimérica, sendo provável que esta técnica possa ser estendida a outros tipos de nanopartículas. (adaptado de webzine Reactive Reports (2005) 48).

Paulo Brito 
A TA INSTRUMENTS é lider mundial em reologia com uma focagem sem paralelo na indústria e investigação.

O compromisso com a inovação é comprovado; o desejo de fazer medidas reológicas melhor do que os seus concorrentes comprova-se pelos contínuos avanços nos seus diferentes produtos. A aquisição da firma Rheometrics permite a oferta de todos os tipos de sistemas existentes no mercado, desde sistemas operando a tensão controlada como sistemas operando a deslocamento controlado. O modelo AR 2000 é o equipamento mais vendido no mercado. Esta unidade possui capacidades de medição sem comparação e um conjunto de acessórios único. Entre outras, podem citar-se:

- Motor de arrastamento, modelado permitindo uma vasta gama linear de torções

- Inércia de baixo valor para o melhor controle de tensão e deslocamento

- Controle directo da tensão e oscilação em toda a gama de trabalho do equipamento

- Desenho ultra robusto do corpo do equipamento

- Transdutor de força manual separado

- Electrónica isolada do resto do equipamento

- Sistemas periféricos de troca rápida e identificação automática (Smart Swap)

- Representação em tempo real da forma de onda em oscilação

- O único sistema de tensão controlada disponível num corpo único de alumínio

\section{UM Nível SUPERIor em CALorimetria}

A TA Instruments fabrica diversos tipos de equipamentos na área da calorimetria. Para além dos calorímetros de varrimento, fornece também equipamento de análise termogravimétrica, equipamentos combinados de DSC/TG, DMA e TMA. O DMA Q800 é o estado da arte em análise dinâmico/mecânica.

A unidade utiliza uma tecnologia semelhante à dos reómetros, de atrito reduzido. $O$ deslocamento é medido utilizando um descodificador óptico que proporciona elevada sensibilidade e resolução. A unidade é utilizada na caracterização de propriedades viscoelásticas de vários tipos de materiais sólidos e é ideal para aplicações em materiais de forte resistência incluindo compósitos.

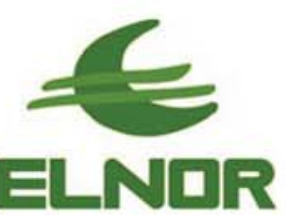

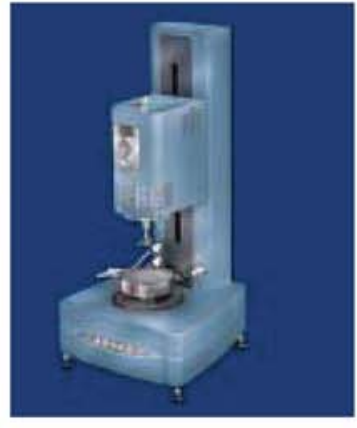

\section{TECNOLOGIA T PARA CALORIMETRIA DIFERENCIAL DE VARRIMENTO (DSC)}

Um desenho superior para desempenhos de alto nível. $\mathrm{O}$ novo sensor $\mathrm{T}_{0}$ melhora a resolução em $300 \%$ comparativamente aos sistemas

tradicionais.

A estabilidade da

linha de base e a sensibilidade

melhoram de uma ordem de magnitude em relação também aqueles sistemas. A possibilidade de automação dá ao utilizador resultados rápidos, reprodutíveis e exactos.

A utilização do chamado DSC modulado, torna a análise dos dados. ainda mais simples, trazendo mais luz à análise de alguns eventos de difícil interpretação.

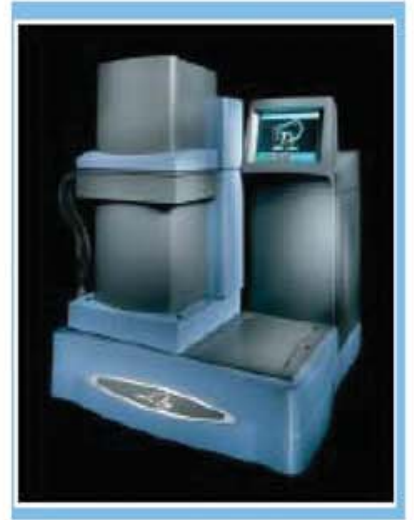

ELNOR - Equipamentos Técnicos e de Laboratório, S.A.

B R.D.Frei Jerónimo de Brito e Melo № 835 • 4465-642 LEÇA DO BALIO • PORTUGAL

$\triangle$ P.O.Box $1019 \bullet 4470$ MAIA CODEX • PORTUGAL

- Phone: (351 22) 9050400

- Fax : (351 22) 9050499 